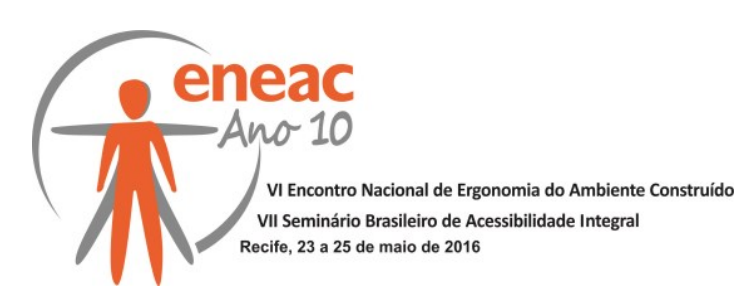

\title{
AVALIAÇÃO PÓS-OCUPAÇÃO: ECOSYS LAGOS ORNAMENTAIS
}

\author{
SOUZA, Paulo Henrique (1); \\ PEGORIN, Gustavo Dutra (2); \\ MICHELAN, Hudson Guerrero (3); \\ LEMOS, Thaiane de Sousa (4); \\ (1) Universidade do Sagrado Coração, Graduando em Arquitetura e Urbanismo \\ e-mail: p.henrique91@live.com \\ (2) Universidade do Sagrado Coração, Graduando em Arquitetura e Urbanismo \\ e-mail: gustavopegorin@gmail.com \\ (3) Universidade do Sagrado Coração, Graduando em Arquitetura e Urbanismo \\ e-mail: hmichelan@gmail.com \\ (4) Universidade do Sagrado Coração, Graduanda em Arquitetura e Urbanismo \\ e-mail: thaiane.lemos@hotmail.com
}

\begin{abstract}
RESUMO
A APO vem se consolidando como uma importante ferramenta na qualidade do edifício construído, essencial em ambientes corporativos, como escritórios, que passam por constante evolução. Nesse contexto, o presente artigo apresenta a Avaliação Pós Ocupacional (APO), desenvolvida para a disciplina de mesmo nome do curso de Arquitetura e Urbanismo da Universidade do Sagrado Coração, realizada no escritório da empresa Ecosys Lagos Ornamentais. A proposta de projeto e as recomendações apresentadas são resultadas da análise crítica dos aspectos positivos e negativos encontrados.
\end{abstract}

Palavras chave: Avaliação Pós Ocupacional; Escritório; Ecosys Lagos Ornamentais.

\begin{abstract}
The POE has been consolidated as an important tool in quality built building, essential in enterprise environments, such as offices, undergoing constant evolution. In this context, this paper presents the Post-Occupancy Evaluation (POE), developed for the discipline of the same name the course of Architecture and Urbanism at the University of Sagrado Coração, held at the offices of Ecosys Lakes Ornamental company. The project proposal and the recommendations made are resulted from the critical analysis of the positive and negative aspects found.
\end{abstract}

Keywords: Post-Occupancy Evaluation; Office, Ecosys Lakes Ornamental. 


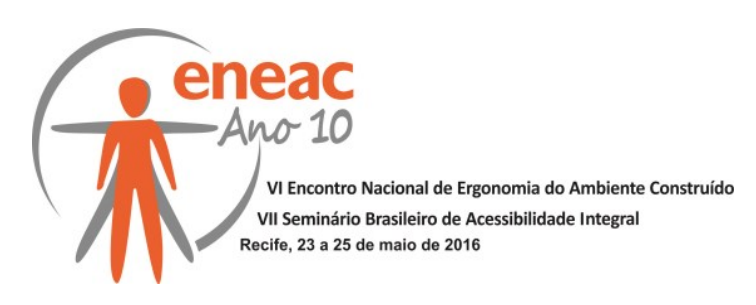

\section{INTRODUÇÃO}

A Avaliação Pós-Ocupação (APO) é um conjunto de métodos e técnicas aplicados ao ambiente no decorrer do uso. Leva em consideração o ponto de vista de especialistas, como arquiteto, engenheiro, designer e psicólogo, compondo uma equipe multidisciplinar cuja percepção sobre o mesmo objeto se distingue, e considera também, o ponto de vista do usuário.

A APO tem como objetivo obter diagnósticos e informações confiáveis sobre o desempenho do ambiente no decorrer do uso, para que estes sirvam de base para futuros projetos. A intenção é trazer informações para que na etapa de menor custo, a etapa de projeto, tenhase mais benefícios, considerando o que se vai construir, com o menor investimento financeiro.

Para a consolidação da Avaliação Pós Ocupacional deste artigo, foi analisado o ambiente utilizado como escritório da Empresa Ecosys Lagos Ornamentais, identificando pontos positivos e negativos do edifício e sugerindo melhorias.

\subsection{Justificativa}

Além de identificar as patologias e sensações dos ocupantes do local, é de extrema importância uma APO em um ambiente comercial, pois através dela pode-se analisar até que ponto a qualidade do edifício está relacionada ou não à produtividade da empresa.

Para MILLER (2015), é essencial que o ambiente corporativo proporcione bem-estar e funcionalidade aos usuários. Segundo o autor, a presença dessas condições proporcionam o aumento da eficiência e produtividade do trabalhador, melhoria da qualidade técnica dos produtos, e redução do desperdício de tempo e de matéria-prima.

A escolha da Ecosys Lagos Ornamentais para o desenvolvimento da Avaliação PósOcupação se deu pelo foco sustentável da empresa, que valoriza o meio ambiente.

\subsection{Objetivos}

Ao desenvolver a Avaliação Pós-Ocupação da Ecosys Lagos Ornamentais, tem-se por objetivos: identificar, especificamente nas áreas funcionais, a maneira como os fatores físico-ambientais lumínicos, térmicos e acústicos apresentam-se na loja física da empresa; a análise e a comparação entre a satisfação do usuário e vistoria técnica; e, por fim, a produção de um projeto de intervenção arquitetônica, em resposta aos resultados obtidos.

\subsection{Metodologia}

O presente artigo se baseou em pesquisas bibliográficas, para o desenvolvimento teórico e projetual. Estabeleceu-se breve contextualização histórica sobre APO e tipologia do edifício estudado.

A avaliação se desenvolveu, cronologicamente, com a coleta de dados; a leitura do projeto executivo; a formulação e aplicação dos questionários, que avaliaram cinco ambientes (recepção, salas de escritório, reunião, logística e banheiros) em 11 quesitos com quatro opções de respostas (ótimo, bom, regular e ruim); a avaliação técnica; a análise e comparação entre os resultados dos usuários e da vistoria; e a elaboração do diagnóstico. 


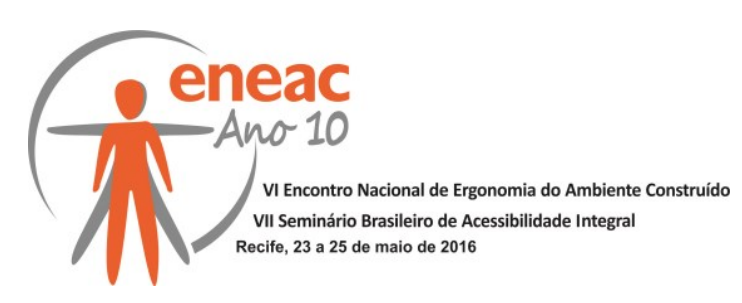

Através da APO realizada, foram elaboradas as recomendações e o projeto de intervenção, para uma futura reforma ou expansão da empresa, elaborado a partir de softwares como AutoCAD e SketchUp.

\section{REVISÃO BIBLIOGRÁFICA}

\subsection{Breve Histórico Avaliação Pós-Ocupação}

A APO, se realizada de forma eficaz, se torna um instrumento de avaliação extremamente importante, diagnosticando as possíveis intervenções e pontos positivos do edifício analisado e fornecendo insumos para o banco de dados que servirão de base para futuras construções e projetos similares.

A preocupação em avaliar o desempenho das edificações só ganhou maior visibilidade e importância após a Segunda Guerra Mundial, diante de construções em larga escala e do baixo desempenho que muitas destas apresentavam. De acordo com Nakamura (2013), no Brasil a Avaliação Pós-Ocupação só começou a ser mais valorizada após a promulgação do Código do Consumidor, no início de 1990, e recentemente com a NBR 15.575, que tem como foco o desempenho das edificações residenciais (ABNT, 2013). Já em países como Japão, França e Inglaterra, este tipo de avaliação é visto como feedback do processo de projeto, ao menos a quarenta anos.

Segundo ORNSTEIN (1996, apud NAKAMURA, 2013), a APO tem como resultado a curto prazo extrair programas de manutenção preventiva e corretiva. Já a médio e longo prazo, tem-se como objetivo acumular informações para contribuir para o aprimoramento de normas e estabelecer diretrizes de projeto.

\subsection{Histórico Escritório}

No contexto de uma APO, observar a história dos escritórios contribui para o entendimento destes como espaço de trabalho, e, nesse sentido, o quanto a arquitetura influência no relacionamento entre funcionários e nas atividades desenvolvidas.

O conceito de escritório, de acordo Saval (2014), surgiu no século XIX, diante das necessidades de banqueiros e advogados por assistentes com quem pudessem dividir suas atividades. O aumento da população de funcionários obrigou então que os empresários procurassem espaços para abrigar os novos colaboradores.

Em contextos históricos, segundo Tozzi (2015), o escritório se tornou uma opção decente ao trabalho braçal. Entre 1860 e 1950, impulsionados pelo capitalismo, surgiram as profissões formais, sem distinção entre vida profissional e pessoal, chefes e subordinados sentavam-se lado a lado, o que estreitava as relações.

O surgimento dos primeiros arranha-céus fornecia status para as organizações e grandes conglomerados, cujo interesse, segundo Saval (2014), era estar sempre no topo dos edifícios e ostentar sua posição. Já a partir da década de 50, o espaço físico passa a se basear em sistemas autoritários, onde chefes e subordinados mantem uma relação fria e altamente baseada em hierarquias.

Entre 1960 á 1990, vários teóricos discorreram sobre formas melhores de trabalho, para McGregor (s/d, apud TOZZI, 2015), era preciso construir um espaço que fosse, ao mesmo tempo, aberto e privado. Surgiram então as baías, porém estas reforçaram o conceito de superioridade, já que apenas os cargos mais altos possuíam uma sala própria. 


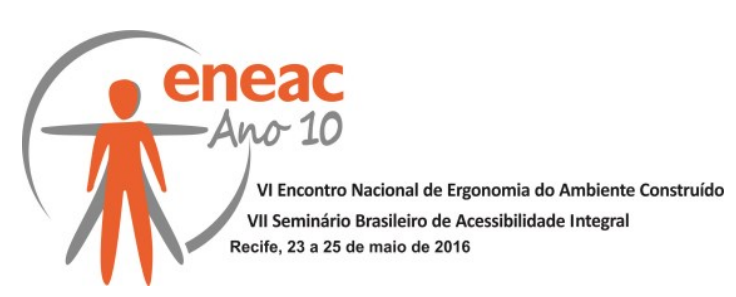

Em 1990, apareceram as primeiras empresas focadas em tecnologia e elas reinventam o design e usabilidade de um escritório, o avanço da tecnologia alterou o layout e a organização dos escritórios, e passa a ocupar lugar de destaque. (SAVAL, 2014).

Atualmente os ambientes de trabalhos são mais tecnológicos e informais, com ênfase maior no trabalho em equipe, o que vêm proporcionando resultados excelentes tanto em produtividade, quanto em qualidade de vida dos funcionários.

\section{A AVALIAÇÃO}

\subsection{Ecosys Lagos Ornamentais}

A Ecosys Lagos Ornamentais esta localizada na cidade de Bauru, estado de São Paulo, na Avenida Comendador José da Silva Martha número 24-28, no bairro Vila Santista.

Sua especialização é a execução de lagos ornamentais e piscinas naturais. Apesar do pequeno porte, a empresa atende a todo o estado de São Paulo, e também realiza projetos fora do estado e país.

A Ecosys esta em processo de crescimento, portando este trabalho visa verificar as falhas e sugerir melhorias em sua sede, para que assim, o ambiente de trabalho beneficie o usuário fazendo com que suas atividades diárias sejam cada vez mais produtivas.

A sede da empresa esta estruturada em dois pavimentos. No térreo (Figura 1), estão localizados os escritórios financeiro e de projeto, a recepção/café e o banheiro (Figura 2).

Figura 01: Implantação Geral Térreo.

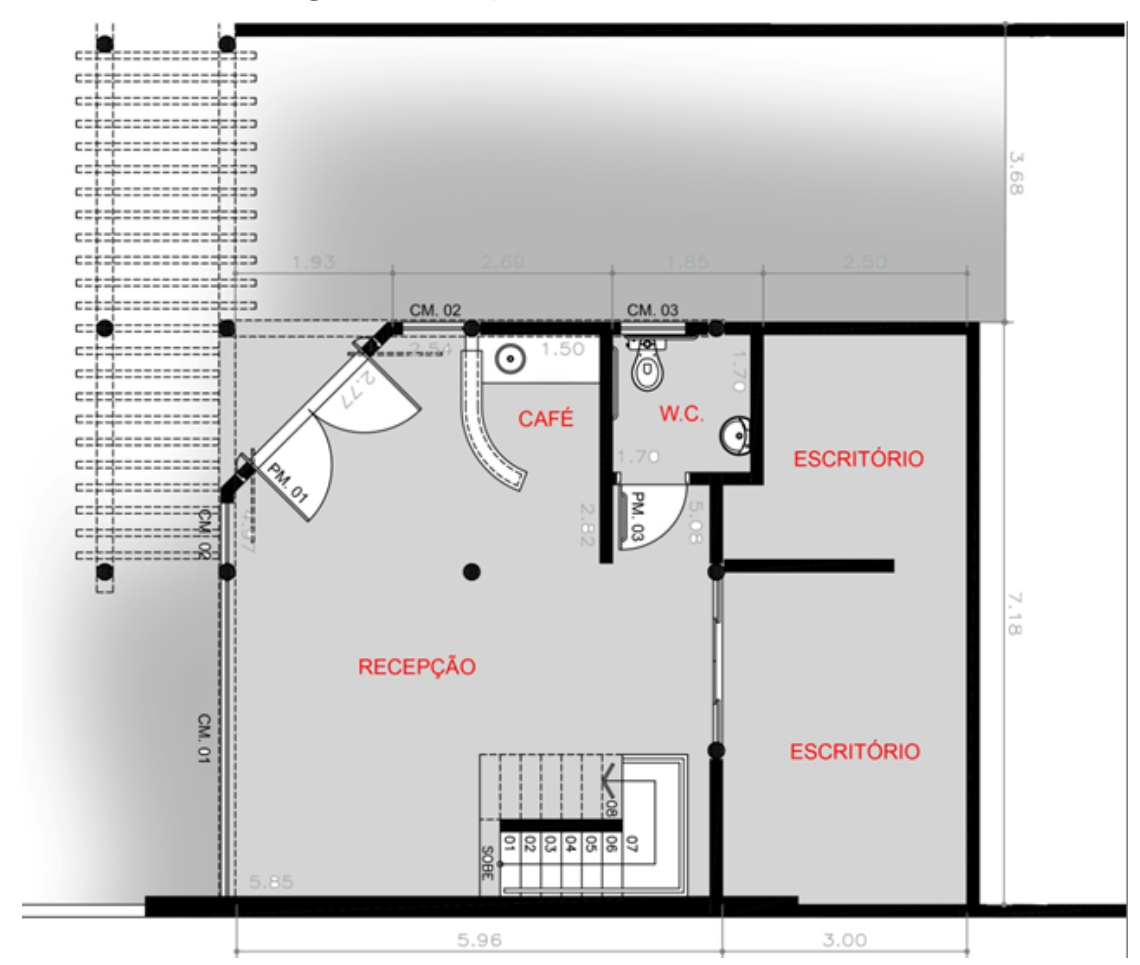

Fonte: Elaborado pelos autores (2015). 


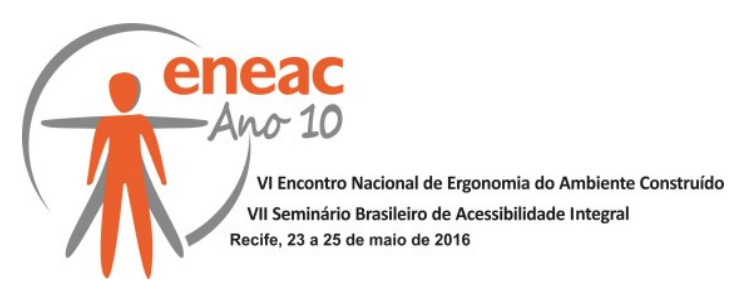

Figura 2: Recepção.

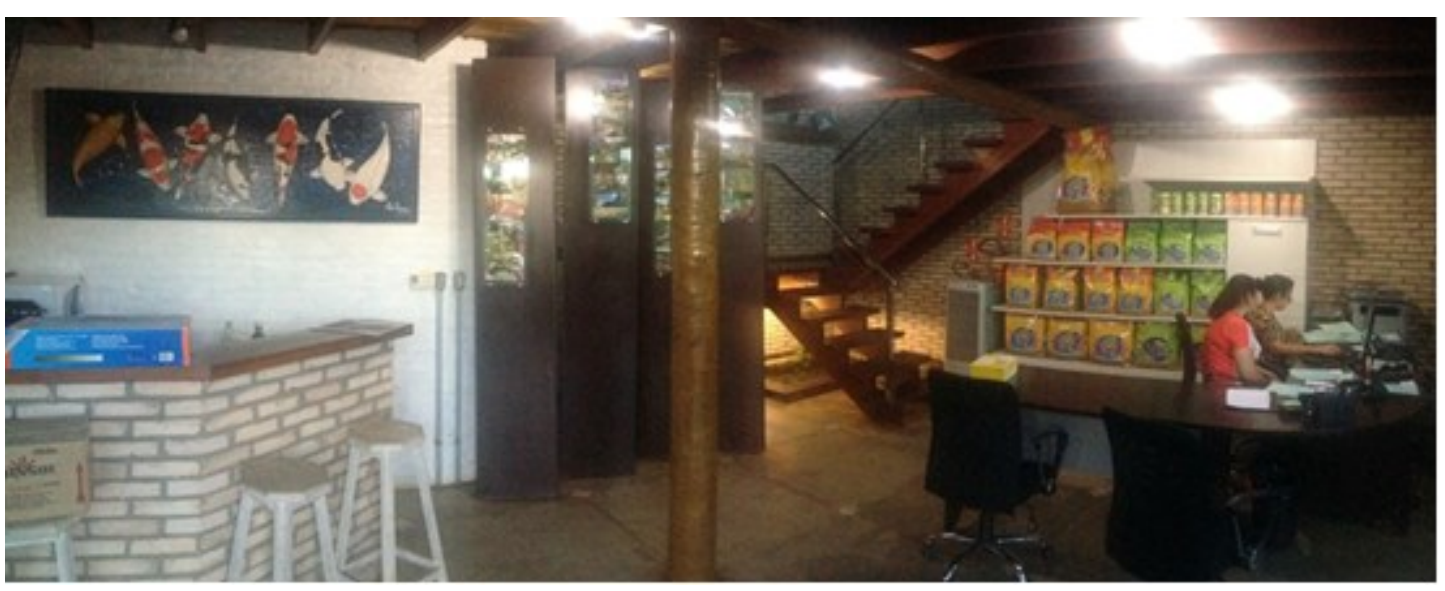

Fonte: Elaborado pelos autores (2015).

Já no segundo piso, conforme Figura 3, estão os escritórios de logística/manutenção (Figura 4) e a sala de reuniões (Figura 5).

Figura 3: Implantação Geral Segundo Pavimento.

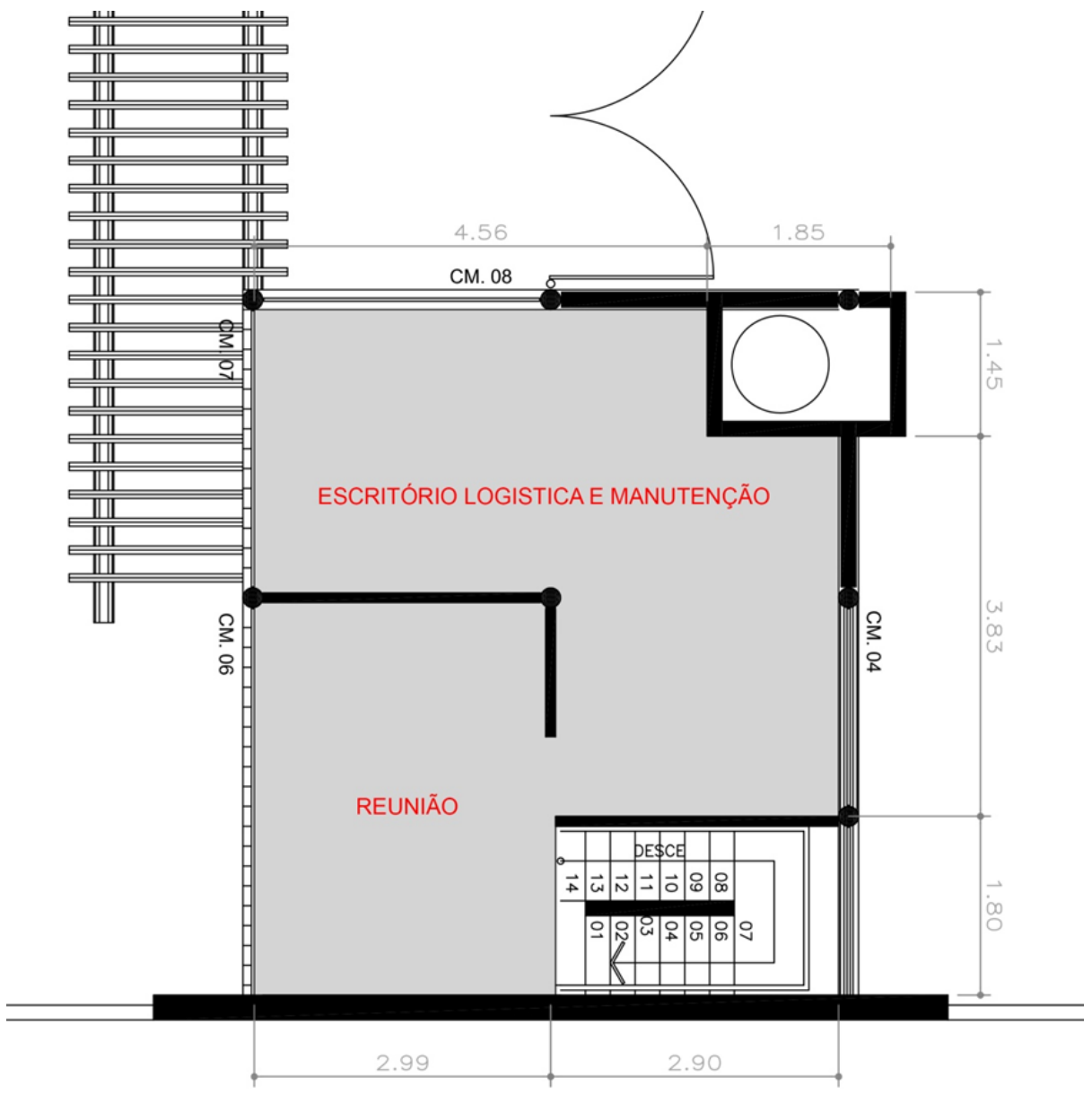

Fonte: Elaborado pelos autores (2015). 


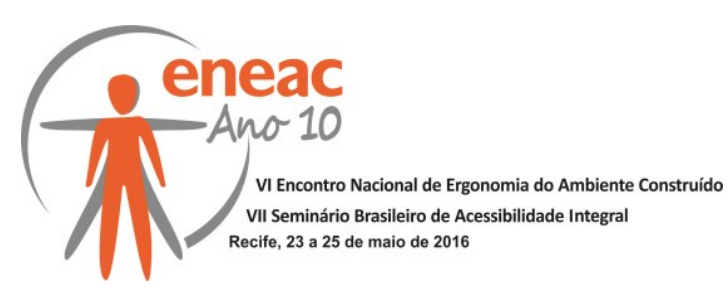

Figura 4: Sala de Logística.

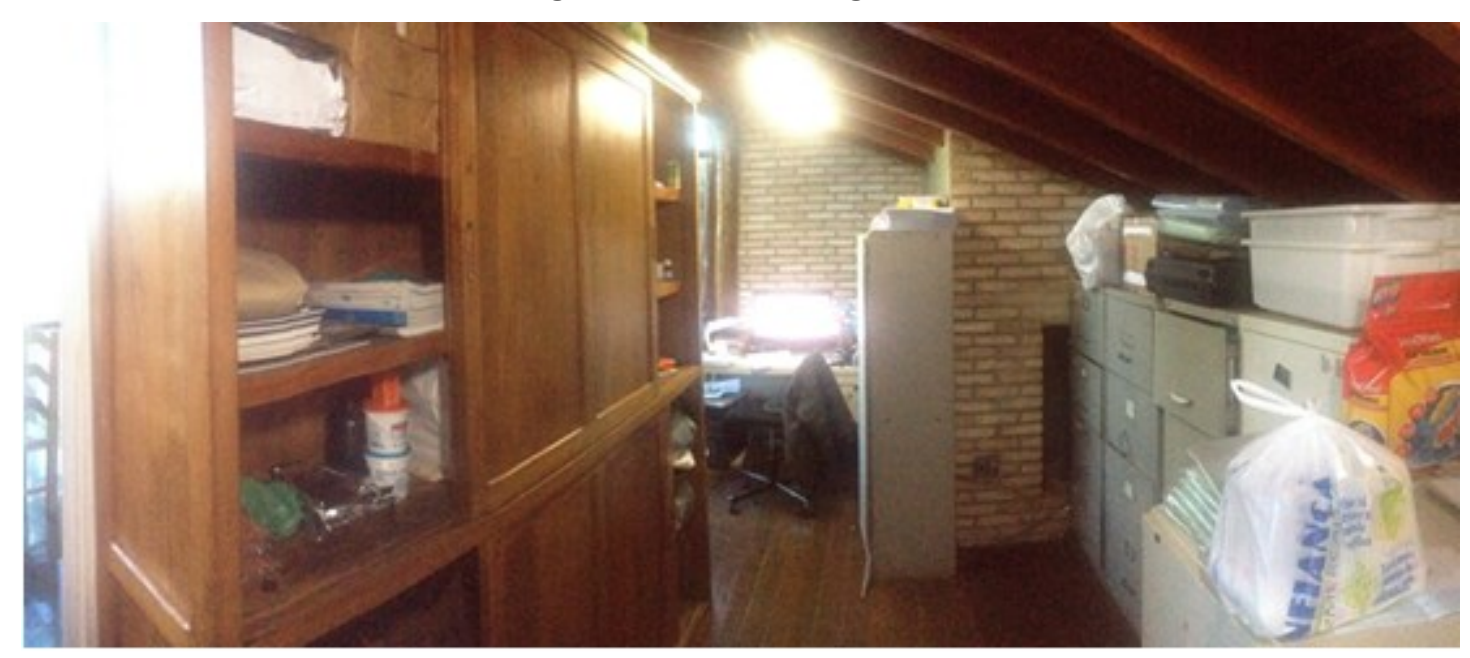

Fonte: Elaborado pelos autores (2015).

Figura 5: Sala de Reuniões.

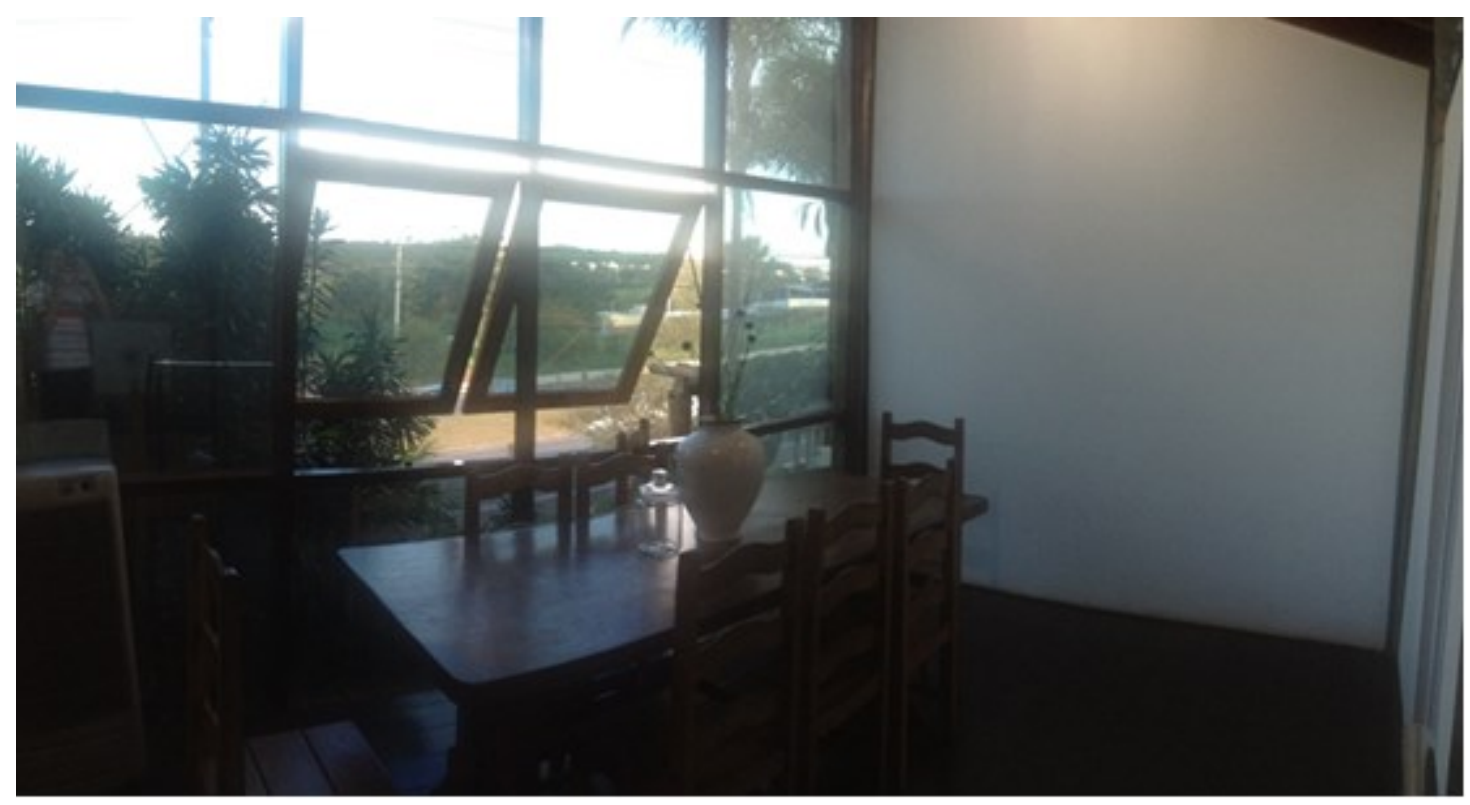

Fonte: Elaborado pelos autores (2015).

\subsection{Avaliação Usuários}

De acordo com a avaliação feita pelos usuários os usos mais problemáticos estão na recepção e no segundo pavimento do edifício. As salas de reunião e de logística apresentaram uma porcentagem ruim de 14\% e 12\% respectivamente (Figuras 6 e 7), com iluminação e ventilação artificiais consideradas insuficientes, situação agravada pela ausência de ar-condicionado. 


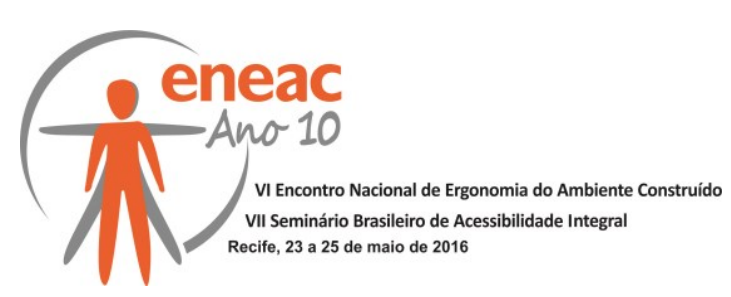

Figuras 6 e 7: Análise do usuário - Condições gerais da sala de reuniões e da sala de logística.
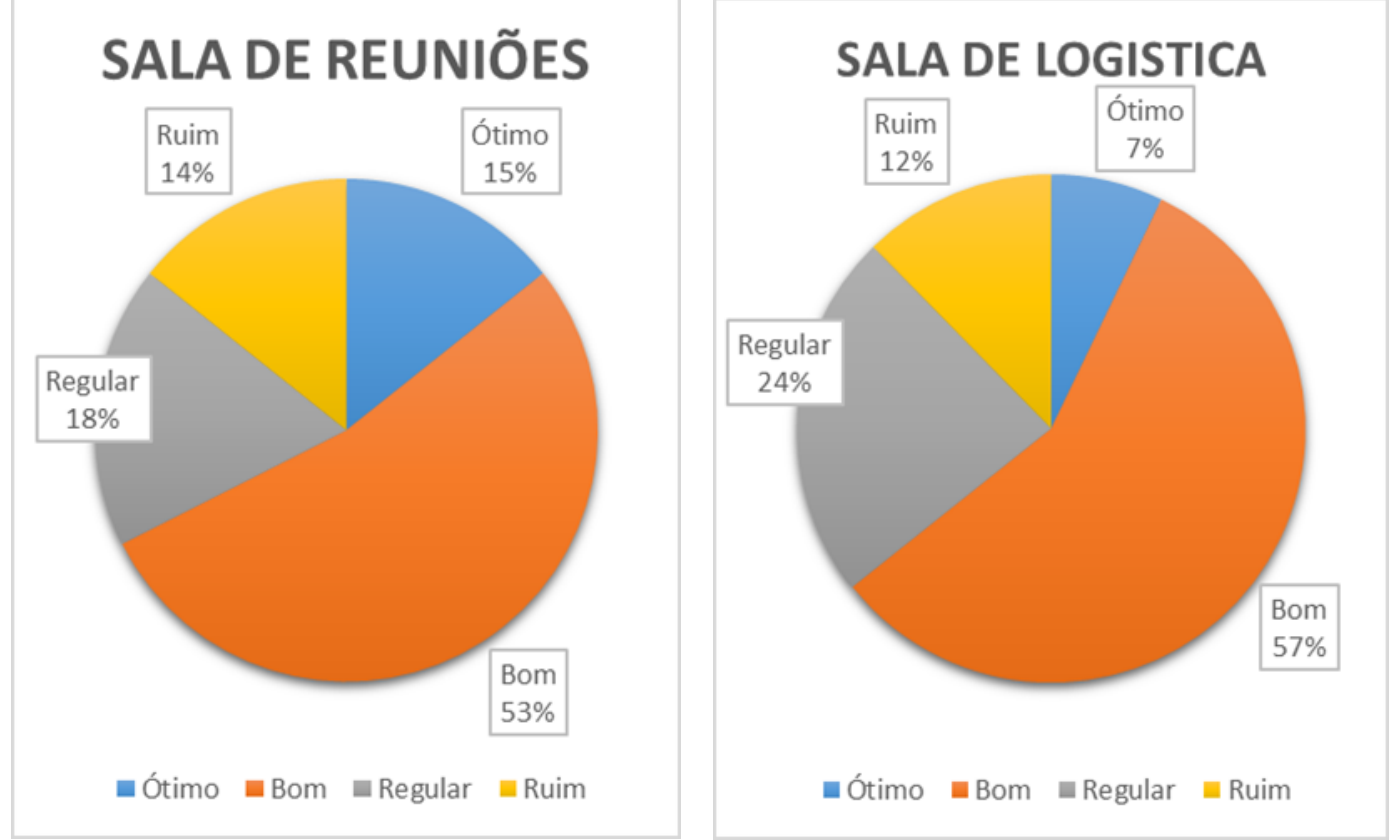

Fonte: Elaborado pelos autores (2015).

O escritório foi o ambiente melhor avaliado (Figura 8), com índices de aprovação (ótimo e bom) de $67 \%$, e apenas $8 \%$ ruim, devido à leve deficiência na iluminação e ventilação naturais. O banheiro também foi considerado bom para $64 \%$ dos usuários (Figura 9), apesar da iluminação natural não ser adequada. Enquanto a Recepção/café alcançou um índice ruim ou regular de $43 \%$ (figura 10 ), com manutenção e isolamento acústico mal avaliados, sendo o ambiente com pior avaliação.

Figura 8: Análise do usuário - Condições gerais da sala de escritório.

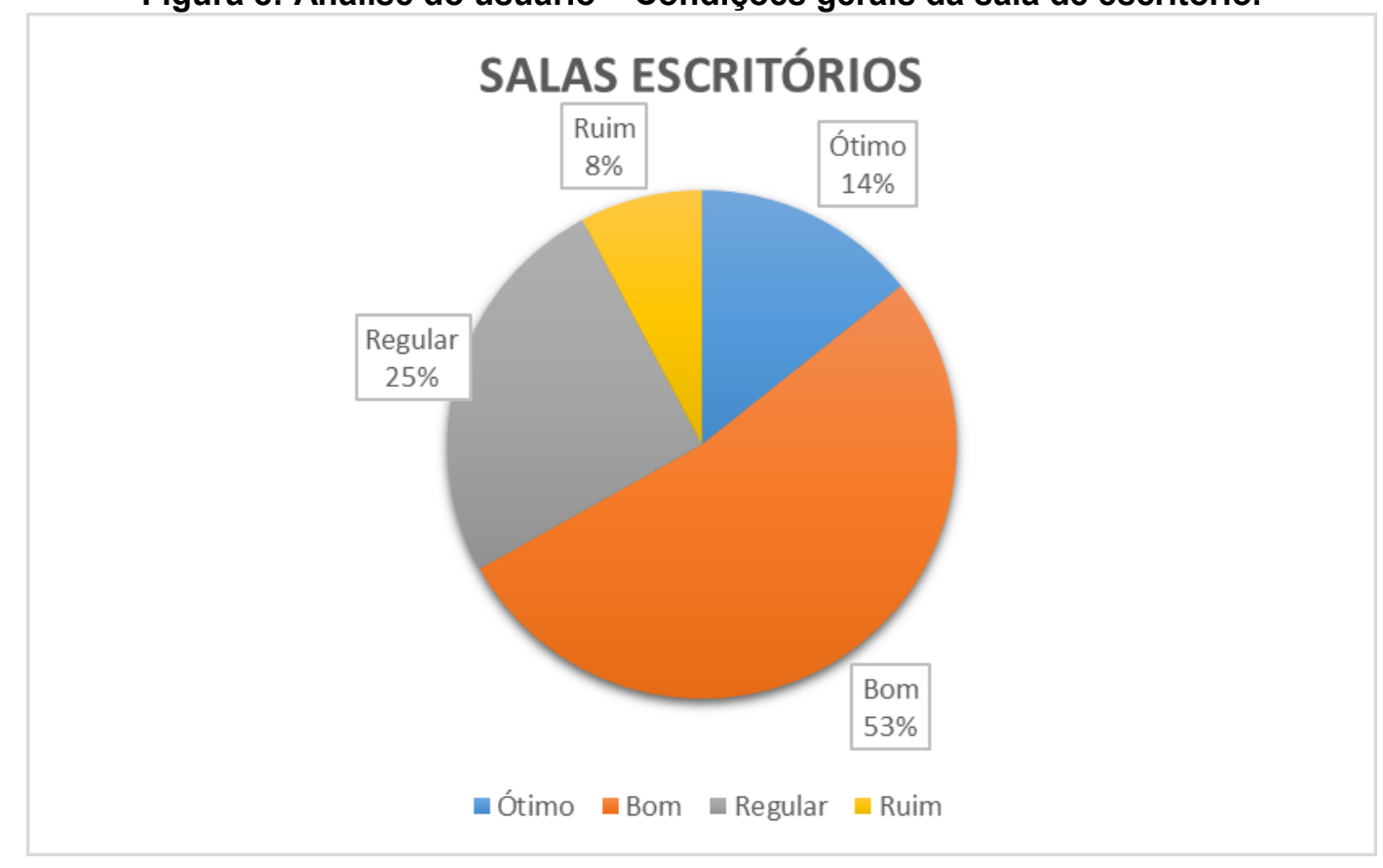

Fonte: Elaborado pelos autores (2015). 


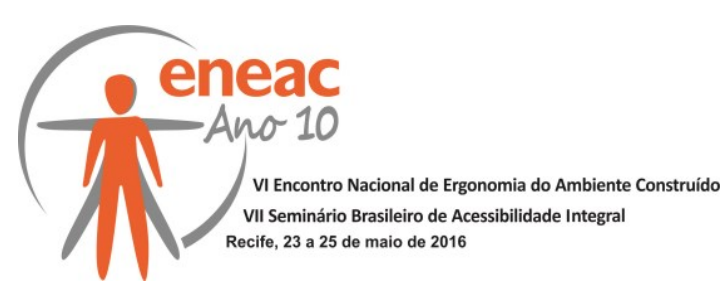

Figuras 9 e 10: Análise do usuário - Condições gerais do banheiro e da recepção.
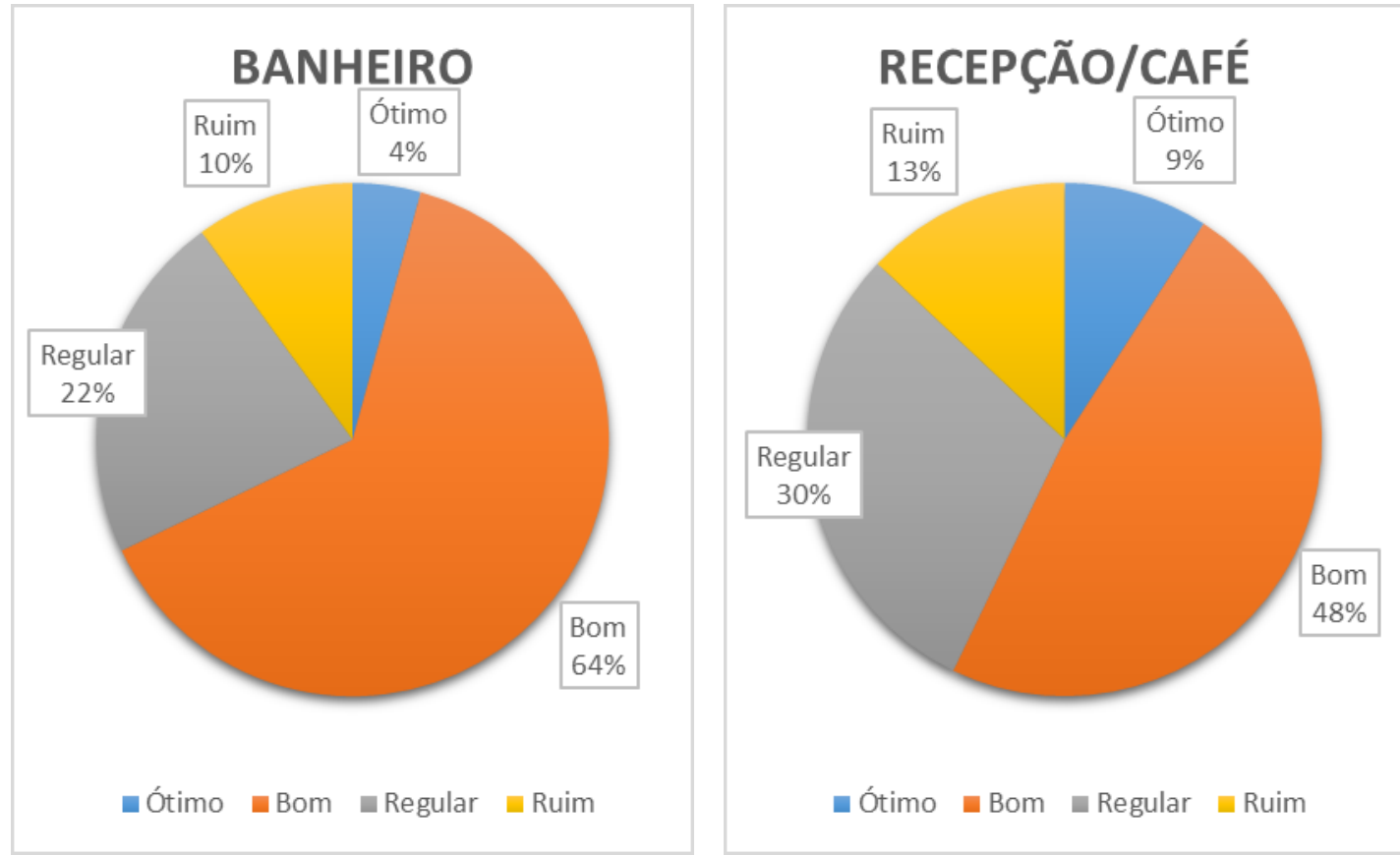

Fonte: Elaborado pelos autores (2015).

\subsection{Avaliação Técnica}

Com base nas avaliações e vistoria técnica, constatou-se iluminação e ventilação natural como boa, embora a climatização não seja adequada em todos os ambientes, exceto nos escritórios, que apresentam o uso de ar-condicionado.

Em geral, a iluminação artificial não é adequada, pois, a intensidade de luz é insuficiente para as atividades praticadas.

Aspectos subjetivos que acabam influenciando o comportamento dos usuários também foram avaliados, quesitos como piso, teto e paredes, se apresentando satisfatórios, mesmo que algumas deles sejam rústicas, de tijolos à vista. Porém estes aspectos não interferem na qualidade das atividades praticadas.

Em todos os setores analisados, o seu tamanho em área, o mobiliário e equipamentos eletrônicos se apresentam em quantidade e qualidade suficientes para 0 bom funcionamento dos setores da empresa.

A situação mais crítica é a manutenção do edifício, embora sua estrutura tenha uma tendência rústica, com pilares e vigas de madeira, o estado é precário, necessitando de reparos imediatos.

\subsection{Resultados}

O confronto dos resultados técnico e dos usuários revelou que manutenção foi um problema recorrente em todos os ambientes analisados, tanto para os técnicos quanto para os usuários. 


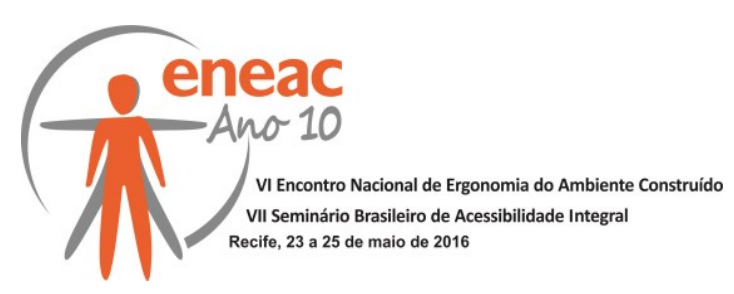

Após a vistoria e aplicação de questionário, observou-se ainda resultados positivos em praticamente todos os itens avaliados, sendo que as alterações necessárias para os ambientes serão de curto à médio prazo, e a longo prazo.

Em curto e médio prazo a recomendação é fazer a manutenção do prédio, a conservação da estrutura de madeira, a troca da iluminação, a instalação de mais ventiladores e aparelhos de ar-condicionado. Em longo prazo a solução é a execução do projeto proposto.

\subsection{Proposta de Projeto}

O projeto desenvolvido para a sede da empresa Ecosys Lagos Ornamentais (Figuras 11 e 12) visa criar novos ambientes, promovendo uma melhora na área de trabalho, além de restaurar sua estrutura existente, a qual remete um estilo rústico, esteticamente atraente.

Para melhorar os ambientes de trabalho, propõe-se alterações em praticamente toda área de escritórios e sala de reuniões. Todos os setores funcionarão no piso térreo com a ampliação de uma sala, um banheiro e a sala de reuniões, estando a última conectada visualmente ao tanque de peixes, que apresenta uma potencialidade paisagística, contribuindo para um ambiente construído mais agradável e produtivo (Figura 11).

Figura 11: Planta do pavimento térreo

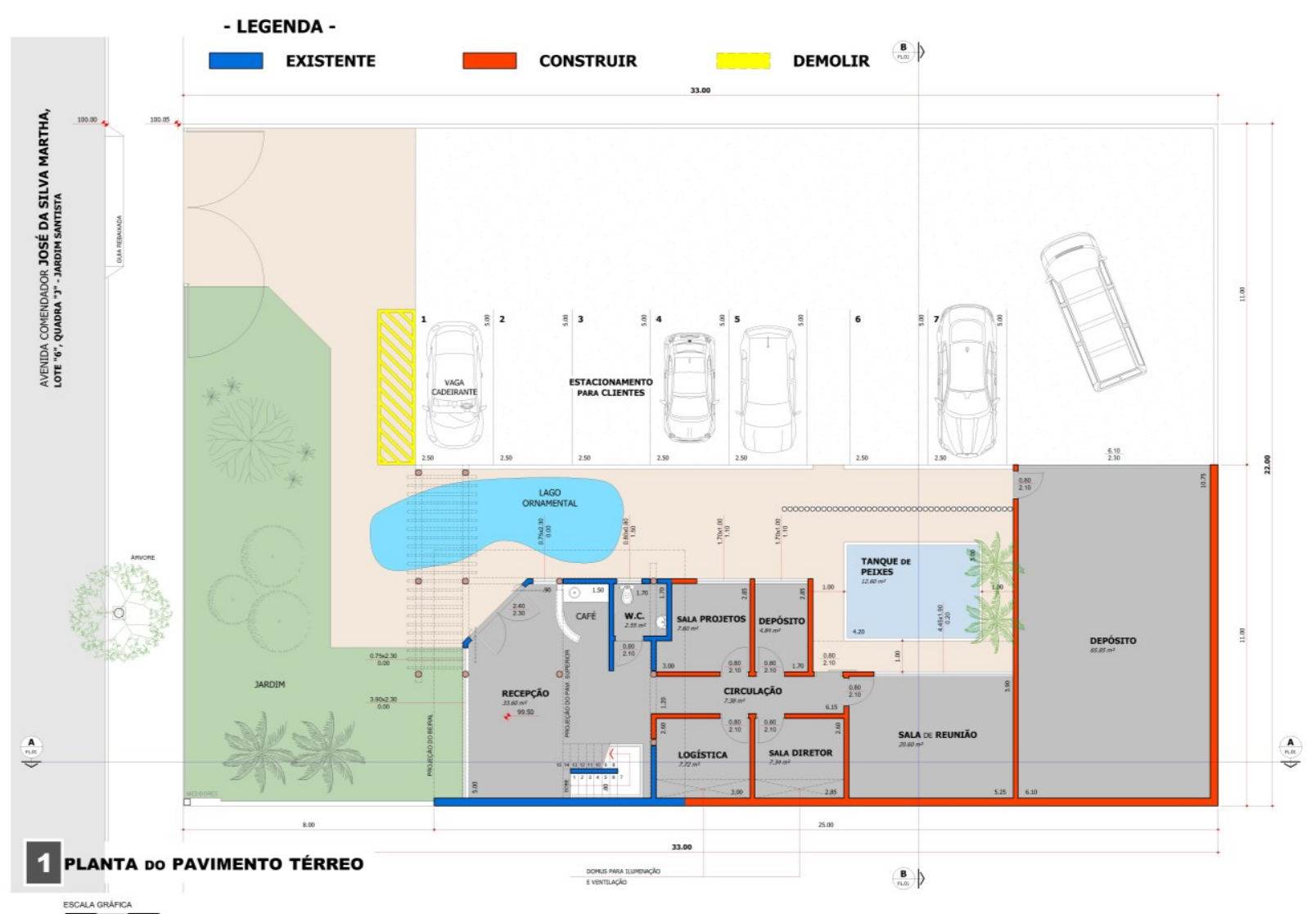

Fonte: Elaborado pelos autores (2015). 


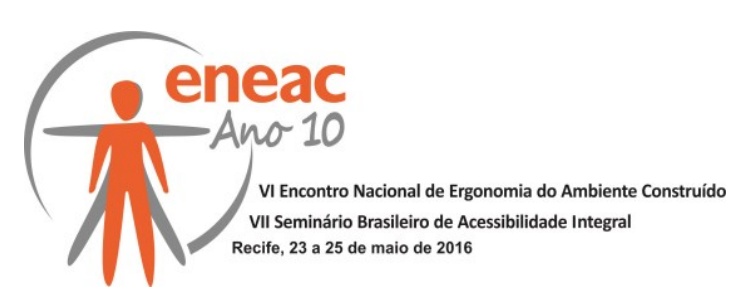

Figura 12: Planta do pavimento superior

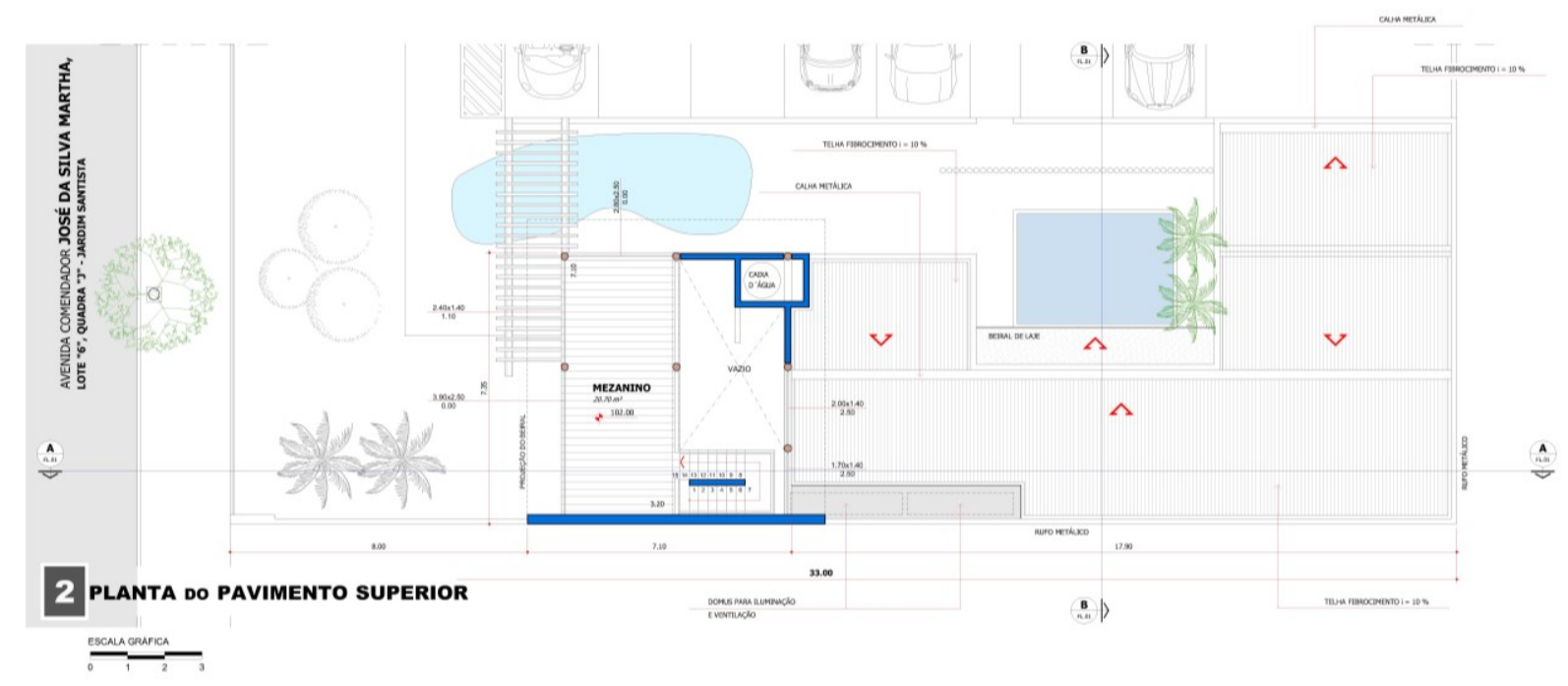

Fonte: Elaborado pelos autores (2015).

A estrutura existente passará por uma reforma que manterá suas características originais (Figura 13), sendo utilizada mais pela sua estética, como fator de atrair clientes, do que pela função, já que todos os setores estarão locados na ampliação (Figuras 14 e 15) no piso térreo. Como grande parte do público que procura a empresa tem por preferência características rústicas em seu projeto, manter estruturalmente pontos originais acaba então remetendo aos clientes o universo o qual buscam, fazendo com que se identifiquem ainda mais com a empresa e os produtos oferecidos.

Figura 13: Elevação Frontal do projeto

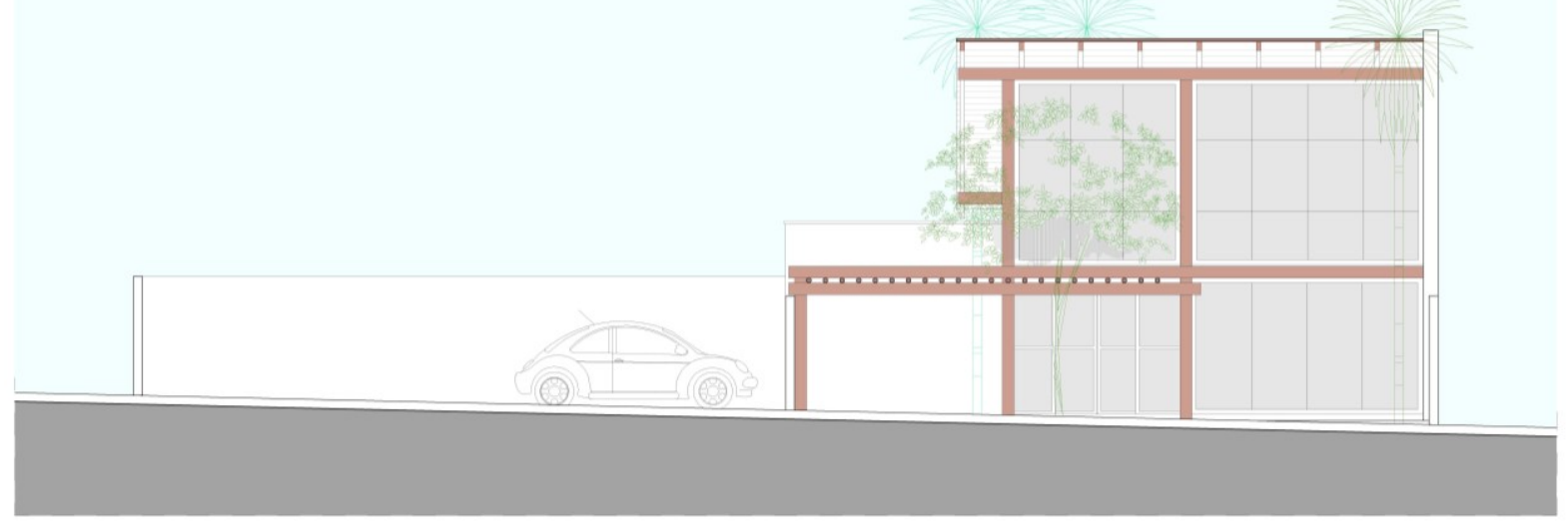

ELEVAÇÃO FRONTAL

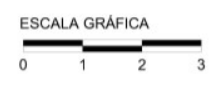

Fonte: Elaborado pelos autores (2015). 


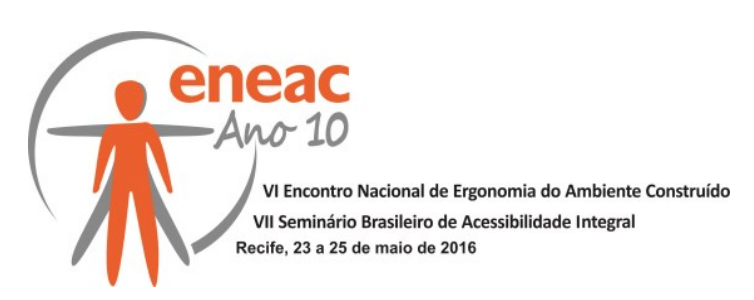

Figura 14: Perspectiva geral projeto

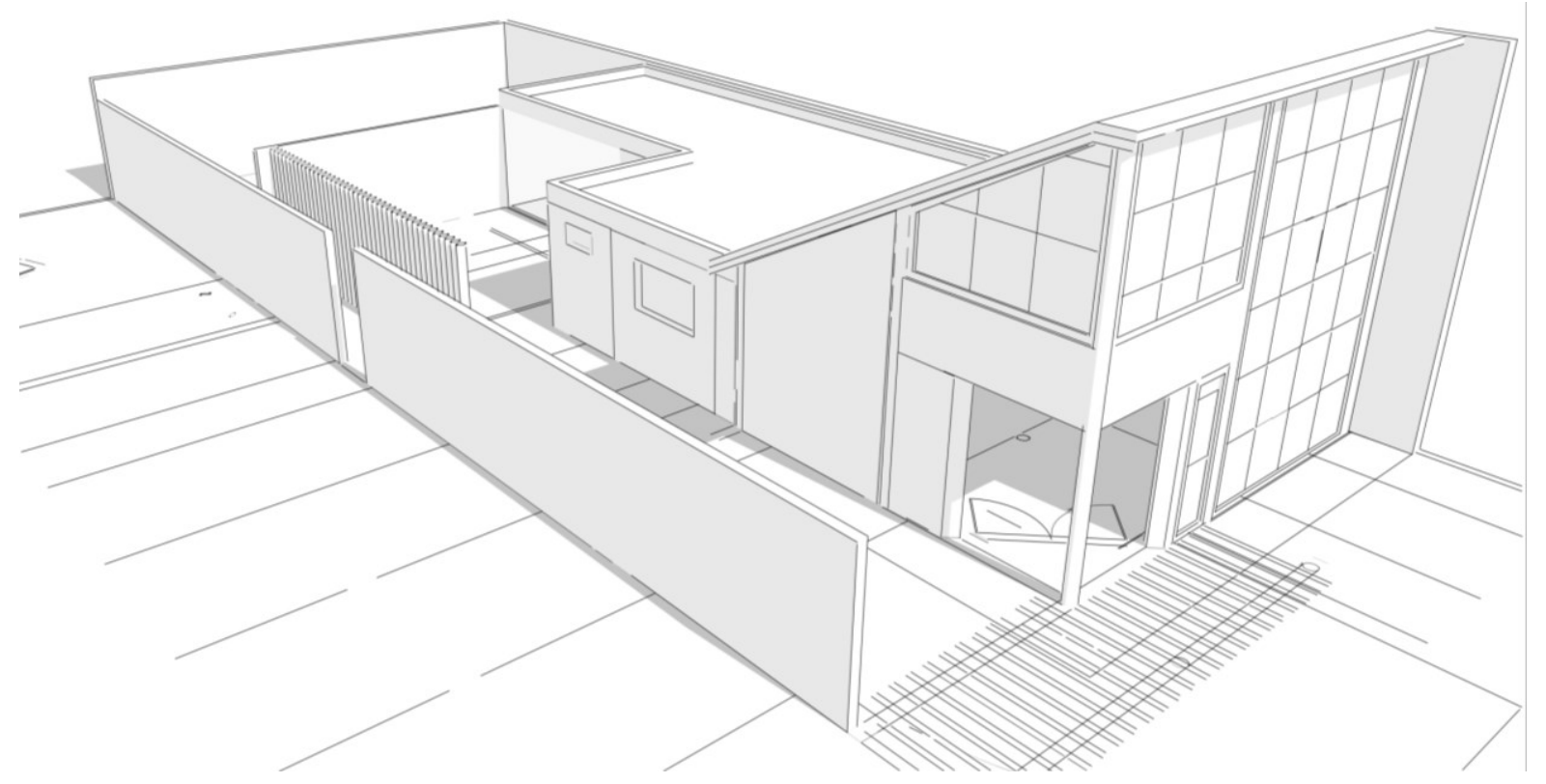

Fonte: Elaborado pelos autores (2015).

Figura 15: Perspectiva geral projeto

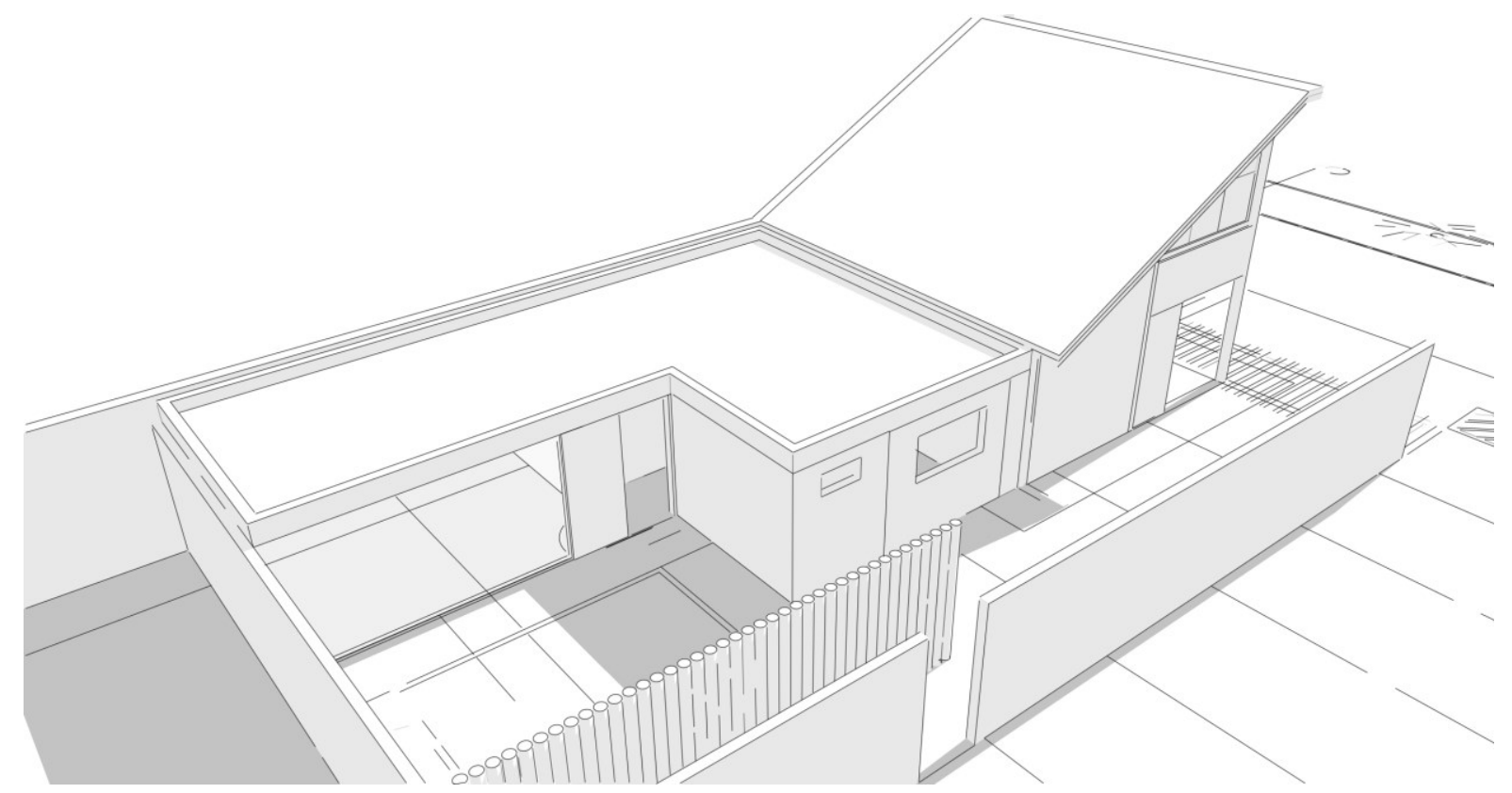

Fonte: Elaborado pelos autores (2015).

\section{CONSIDERAÇÕES FINAIS}

A realização da Avaliação Pós Ocupacional confirma que muitas empresas acabem não investindo adequadamente em suas áreas funcionais, não visíveis ao publico consumidor, o que acaba prejudicando a qualidade desses ambientes e por consequência à própria produtividade. 


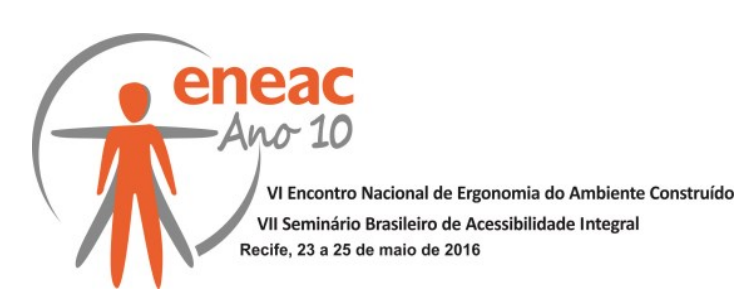

Contudo, a mesma APO fornece subsídios para reverter essa situação, tanto em ambientes já edificados, através de recomendações e intervenções, quanto para futuros projetos, devido à contribuição ao repertório projetual do arquiteto e profissionais envolvidos.

\section{REFERÊNCIAS BIBLIOGRÁFICAS}

Associação Brasileira de Normas Técnicas (ABNT) NBR 15.575: Edificações Habitacionais Desempenho. Rio de Janeiro: ABNT, 2013.

MILLER, Herman. Como projetar ambientes corporativos com alta produtividade. ArchDaily Brasil, 14 Mai 2015. Disponível em: <http://www.archdaily.com.br/br/766792/como-projetarambientes-corporativos-com-alta-produtividade> Acessado em: 20 Mai 2015.

NAKAMURA, Juliana. Como fazer a avaliação pós-ocupação. Revista AU, edição 237, Editora Pini, Dez 2013. Disponível em: http://au.pini.com.br/arquitetura-urbanismo/237/como-fazer-a-avaliacaopos-ocupacao-302156-1.aspx. Acessado em 16 Mai 2015.

SAVAL, Nikil. Cubículo - A História Secreta do Escritório. Rio de Janeiro: Editora Rocco, 2015.

TOZZI, Elisa. Escritório: história de produtividade, desconforto e poder. Revista Você S/A, Editora Abril, 26 Jun 2014. Disponível em: http://exame.abril.com.br/revista-vocesa/edicoes/193/noticias/escritorio-historia-de-produtividade-desconforto-e-poder. Acesso em 16 Mai 2015.

\section{AGRADECIMENTOS}

Em especial a Professora Me. Giovana Innocenti Strabeli, que ministrou a disciplina Avaliação Pós Ocupacional e nos apresentou a este vasto campo de pesquisa, agradecemos também aos funcionários e ao proprietário da Ecosys Lagos Ornamentais, Guy Retz Godoy dos Santos, pela solicites, boa vontade e colaboração na pesquisa. 